\title{
Prolonged parasite clearance in a Chinese splenectomized patient with falciparum malaria imported from Nigeria
}

Hong-Wei Zhang ${ }^{{ }^{* \dagger}}$, San-Jin $\mathrm{Li}^{2 \dagger}$, Tao Hu${ }^{3+}$, Yong-Min Yu², Cheng-Yun Yang ${ }^{1}$, Rui-Min Zhou', Ying Liu', Jing Tang ${ }^{2}$, Jing-Jing Wang ${ }^{2}$, Xiu-Yun Wang ${ }^{2}$, Yong-Xiang Sun ${ }^{2}$, Zhan-Chun Feng ${ }^{3}$ and Bian-Li Xü ${ }^{*}$

\begin{abstract}
Background: The spleen plays a pivotal role in the rapid clearance of parasitized red blood cells in patients with falciparum malaria after artemisinin treatment. Prolonged parasite clearance can be found in patients who have had a splenectomy, or those with hemoglobin abnormalities and/or reduced immunity, which are all distinguishable from artemisinin resistance. This paper reports on a case of prolonged parasite clearance in a Chinese splenectomized patient with falciparum malaria imported from Nigeria.

Case presentation: A 35-year-old Chinese male suffered 2 days of febrile illness after returning to Zhumadian city of Henan province from Nigeria on October 1, 2014. The main symptoms were febrile, including the highest axillary temperature of $40{ }^{\circ} \mathrm{C}$, headache, and chills. A peripheral blood smear showed parasitemia (53 913 asexual parasites/ $\mu$ l) of Plasmodium falciparum. The patient had not used any chemoprophylaxis against malaria in Nigeria when he worked there as a construction worker between 2009 and 2014. The patient had three episodes of malaria in Nigeria and had a splenectomy due to a traffic accident 8 years ago from the time he was admitted to hospital. The patient was orally administrated a total of $320 \mathrm{mg} / 2.56 \mathrm{~g}$ dihydroartemisinin-piperaquine for 2 days and intravenously administrated a total of $3000 \mathrm{mg}$ artesunate for 18 days. The axillary temperature of the patient ranged between 37.0 and $37.7^{\circ} \mathrm{C}$ from Day 0 to Day 3, and blood microscopy revealed falciparum malaria parasitemia (26 674 asexual parasites/ $\mu$ l) on Day 3. The patient was afebrile on Day 4, falciparum malaria parasitemia was continuously present and then gradually decreased on the next days, and was negative on Day 21. The patient was cured and left hospital on Day 24 after no plasmodium falciparum was found in the blood on Day 21 to Day 23. No mutation was found in the K13 propeller gene when compared with the PF3D7_1343700 K13 propeller gene reference sequence.
\end{abstract}

Conclusions: This is the first reported case in China of prolonged parasite clearance in a splenectomized patient with imported falciparum malaria. Artemisinin resistance should be distinguished when prolonged parasite clearance is found in a malaria patient who has had splenectomy.

Keywords: Falciparum malaria, Artemisinin treatment, Prolonged parasite clearance, Splenectomy, China, Nigeria

\footnotetext{
*Correspondence: Zhwei69@163.com; Bianlixu@163.com

${ }^{\dagger}$ Equal contributors

${ }^{1}$ Department of Parasite Disease Control and Prevention, Henan Center for

Disease Control and Prevention, Zhengzhou, People's Republic of China

Full list of author information is available at the end of the article
} 


\section{Multilingual abstract}

Please see Additional file 1 for translations of abstract into five official working languages of the United Nations.

\section{Background}

In humans, the spleen is the largest secondary immune organ in the body. Important functions of the spleen include removal of old and abnormal blood cells, removal of circulating pathogens, and facilitating the development of immune responses against Plasmodium [1]. It has been shown that the spleen plays an active role in the retention and removal of malaria-infected red blood cells (RBCs) from blood circulation, as well as a key role in the development of immune responses directed against parasites [2]. Parasite clearance rates are influenced by many factors, including insufficient artesunate and dihydroartemisinin levels in the blood, pharmacokinetics, pharmacodynamics, splenectomy, hemoglobin abnormalities, and reduced immunity, which may delay parasite clearance [3, 4]. The World Health Organization's (WHO's) classification of antimalarial drug efficacy (parasitemia on Day three with axillary temperature $\geq$ $37.5{ }^{\circ} \mathrm{C}$ ) [5] may not apply to asplenic patients. This paper reports a case of prolonged parasite clearance in a splenectomized Chinese worker with falciparum malaria imported from Nigeria.

\section{Case presentation}

A 35-year-old Chinese male was admitted to the $6^{\text {th }}$ People's Hospital in Zhengzhou, China on October 6, 2014, because he had a fever with the highest axillary temperature of $40{ }^{\circ} \mathrm{C}$, headache, and chills. Prior to admission, the patient had suffered 2 days of febrile illness after returning from Nigeria on October 1, 2014. The patient had not used chemoprophylaxis against malaria in Nigeria when he worked there as a construction worker between 2009 and 2014. The patient had three episodes of malaria and had been administrated quinine, but stopped treatment as soon as he was afebrile. The patient also had a splenectomy due to a traffic accident 8 years ago from the time he was admitted to hospital.

Upon admission, the patient's axillary temperature was $37.2{ }^{\circ} \mathrm{C}$, his pulse rate was 75 beats/min, his blood pressure was $93 / 79 \mathrm{mmHg}$, and his weight was $86 \mathrm{~kg}$. Initial laboratory test results were almost normal except for a high C-reactive protein level of $35.8 \mathrm{mg} / \mathrm{L}$ and a low kalaemia level of $3.30 \mathrm{mmol} / \mathrm{L}$ (see Table 1). Giemsastained thick and thin blood films were microscopically examined and the peripheral blood smear showed parasitaemia of Plasmodium falciparum. Microscopy experts at the Henan Center for Disease Control and Prevention confirmed this result. The density of malarial parasites was 53913 asexual parasites/ $\mu$ l on Day 0. A rapid diagnostic test (Wondfo Biotech Co., Ltd, China) was also
Table 1 Pre-treatment blood result

\begin{tabular}{|c|c|c|}
\hline Variable & Value & Reference value \\
\hline \multicolumn{3}{|l|}{ Hematology } \\
\hline Leukocytes & $6.93 \times 10^{9} / \mathrm{L}$ & $4-10 \times 10^{9} / \mathrm{L}$ \\
\hline Neutrophil & $84.11 \%$ & $45 \sim 77 \%$ \\
\hline Lymphocyte & $10.52 \%$ & $20-40 \%$ \\
\hline Monocyte & $4.50 \%$ & $3-8 \%$ \\
\hline Eosinophil & $0.60 \%$ & $0.5-5 \%$ \\
\hline Basophil & $0.30 \%$ & $0-1 \%$ \\
\hline Erythrocytes & $5.08 \times 10^{12} / \mathrm{L}$ & $3.5-5.5 \times 10^{12} / \mathrm{L}$ \\
\hline Hemoglobin & $155 \mathrm{~g} / \mathrm{L}$ & 110-160 g/L \\
\hline Hematocrit & $46 \%$ & $36-50 \%$ \\
\hline Platelets & $192 \times 10^{9} / \mathrm{L}$ & $100-300 \times 10^{9} / \mathrm{L}$ \\
\hline $\mathrm{HCT}$ & 46.40 & $36.6-50 \%$ \\
\hline MCV & 89.70 & $86-100 \mathrm{fl}$ \\
\hline $\mathrm{MCH}$ & 30.80 & $26-31 \mathrm{pg}$ \\
\hline $\mathrm{MCHC}$ & 343.00 & $310-370 \mathrm{~g} / \mathrm{L}$ \\
\hline \multicolumn{3}{|l|}{ Blood chemistry } \\
\hline AST & $18 \mathrm{IU} / \mathrm{L}$ & $<40$ \\
\hline ALT & $40 \mathrm{IU} / \mathrm{L}$ & $<40$ \\
\hline LDH & $151 \mathrm{IU} / \mathrm{L}$ & $110-240$ \\
\hline Y-GTP & $47 \mathrm{IU} / \mathrm{L}$ & $<40$ \\
\hline Total bilirubin & $14.2 \mu \mathrm{mol} / \mathrm{L}$ & $3.0-21.0$ \\
\hline BUN & $4.5 \mathrm{mmol} / \mathrm{L}$ & $3.2-7.1$ \\
\hline Creatinine & $91 \mu \mathrm{mol} / \mathrm{L}$ & 44-133 \\
\hline Uric acid & $282 \mu \mathrm{mol} / \mathrm{L}$ & $201-430$ \\
\hline Sodium & 134 mmol/L & $135-145$ \\
\hline Potassium & $3.30 \mathrm{mmol} / \mathrm{L}$ & $3.5-5.5$ \\
\hline Chloride & $97 \mathrm{mmol} / \mathrm{L}$ & $98-110$ \\
\hline CRP & 35.8 mg/L & $0.10-8.20$ \\
\hline
\end{tabular}

Abbreviations: ALT alanine aminotransferase, AST aspartate aminotransferase, $B U N$ blood urea nitrogen, $C R P$ C-reactive protein, $H C T$ Hematocrit, $L D H$ lactic dehydrogenase, $\mathrm{MCH}$ mean corpuscular hemoglobin, $\mathrm{MCHC}$ mean corpuscular hemoglobin concentration, MCV erythrocyte mean corpuscular volume, $\gamma$-GTP gamma-glutamyl transpeptidase

positive for malarial antigen. DNA of $P$. falciparum was identified by nested polymerase chain reaction (PCR) amplification of the small-subunit ribosomal ribonucleic acid (18ssrRNA) genes. The K13 propeller gene was amplified using nested PCR and sequenced. No mutations were found when this gene was compared to the PF3D7_1343700 K13 propeller gene reference sequence retrieved from the National Center for Biotechnology Information (NCBI) database.

The patient was intravenously administered artesunate (120 mg first time; then $60 \mathrm{mg}$ every six hours) for 4 days and intravenously treated with the antibiotic ceftriaxone ( $2.0 \mathrm{~g}$ per day) for 4 days. After 72 hours of treatment, the axillary temperature of the patient was $37.4{ }^{\circ} \mathrm{C}$ and 
the density of falciparum parasites was 26674 asexual parasites/ $\mu$ l (see Table 2). The patient was continuously intravenously administered artesunate $(60 \mathrm{mg}$ every $8 \mathrm{~h}$ for 9 days; $60 \mathrm{mg}$ every $12 \mathrm{~h}$ for 1 day; $60 \mathrm{mg}$ every day for 4 days) with antibiotic ceftriaxone of $2.0 \mathrm{~g}$ per day for 14 days. The patient was afebrile on Day 4 but blood microscopy revealed the continuous presence of parasitaemia with densities between 16133 and 34356 asexual parasites/ $\mu l$. The patient was orally administrated dihydroartemisininpiperaquine $(40 \mathrm{mg} / 0.32 \mathrm{~g}$ per tablet, two tablets twice per day) for 2 days from Day 10. The parasitemia declined slowly and morphology of the parasites in the blood films, with pyknotic nuclei and shrunken cytoplasm, suggested that they were dead. Falciparum parasitaemia was negative on Day 21. The patient was cured and left hospital on Day 24 after no plasmodium falciparum was found in the blood on Day 21 to Day 23.

Table 2 Parasite density and body temperature of patient

\begin{tabular}{lll}
\multicolumn{2}{l}{ during hospital stay } \\
\hline Day & Temperature $\left({ }^{\circ} \mathrm{C}\right)$ & $\begin{array}{l}\text { Parasite density } \\
\text { (asexual parasites/ } \mu \text { l) }\end{array}$ \\
\hline 0 & 37.2 & 53913 \\
1 & 37.0 & 30581 \\
2 & 37.7 & 30545 \\
3 & 37.4 & 26674 \\
4 & 36.5 & 34356 \\
5 & 36.6 & 31701 \\
6 & 36.2 & 23896 \\
7 & 36.5 & 25316 \\
8 & 37.2 & 21982 \\
9 & 37.5 & 16133 \\
10 & 37.5 & 19847 \\
11 & 36.5 & - \\
12 & 37.2 & 16434 \\
13 & 36.3 & - \\
14 & 36.2 & 2962 \\
15 & 36.3 & - \\
16 & 36.2 & 3211 \\
17 & 36.3 & - \\
18 & 36.7 & 2688 \\
19 & 35.9 & - \\
20 & 36.7 & 364 \\
21 & 36.5 & 0 \\
22 & 36.0 & 0 \\
23 & 36.4 & 0 \\
\hline & &
\end{tabular}

\section{Discussion}

Malaria had a wide geographical distribution in China but this has decreased dramatically due to the strengthening of malaria control measures in recent decades, especially in the Yunnan and Hainan provinces, and Huanghuai region [6-8]. No locally transmitted malaria cases have been reported since 2012, but imported malaria has increased remarkably in Henan, which may cause secondary spread and antimalarial drug resistance. In 2014, 216 imported malaria cases were reported, which was 24 times higher than the nine imported cases in 2005 in this province [9]. With increasing travel and migration, imported malaria has become a major public health challenge [10-12] and poses a severe threat to the malaria elimination program in China [13]. The WHO currently recommends artemisinin-based combination therapies (ACTs) as the first-line treatment for uncomplicated P. falciparum malaria [14], and oral dihydroartemisinin-piperaquine tablets are most commonly used in China [15]. Typically, a 3-day treatment course with an ACT reduces parasite densities and 95\% of patients' malaria blood slide test results are negative $48 \mathrm{~h}$ after treatment [16]. The emergence of artemisinin resistance, evidenced by delayed parasite clearance after artemisinin treatment, poses a serious threat to the global control of malaria. Artemisinin resistance is characterized by a reduced susceptibility of the ring stage of parasite development. It was first documented in western Cambodia $[17,18]$ and is now prevalent across an expanding area of Southeast Asia, including in Cambodia [19-21], Thailand [22, 23], and the ThaiMyanmar border [24].

Over the past decade, African countries have transitioned from using chloroquine or sulfadoxinepyrimethamine to ACTs as a first-line policy for treating uncomplicated malaria [25]. Although ACT-resistant malaria is rare in Africa, there is a historical precedence of resistance to antimalarial medicine emerging in Asia and spreading to Africa [26]. Three cases of early treatment failure due to possible ACT-resistant $P$. falciparum malaria have been reported in Nigeria [27]. There has also been a case of possible artemether-lumefantrine treatment failure in an Italian traveler with uncomplicated P. falciparum malaria imported from the Democratic Republic of the Congo [28]. Routine monitoring is needed to ensure that the recommended first-line ACTs are effective for timely changes in national treatment policies and for the early detection of artemisinin resistance.

Prolonged parasite clearance is the basis for the current WHO working definition of artemisinin resistance [5] but it may not applicable for patients who have had a splenectomy [29-31]. In the case reported in this paper, blood microscopy revealed that falciparum 
parasitemia was continuously present and was negative on Day 20 after artemisinin treatment. According to the WHO classification of antimalarial drug efficacy (parasitemia on Day three with axillary temperature $\geq 37.5^{\circ} \mathrm{C}$ ) [5], the patient was considered an early treatment failure for the first time in China. Actually, it is caused by splenectomy but not artemisinin resistance.

The spleen is responsible for initiating immune reactions to blood-borne antigens and for filtering the blood of foreign material, and old or damaged RBCs. It plays a crucial role in the defense against infections with viruses, bacteria, fungi, and parasites [32]. The spleen plays a pivotal role in the rapid clearance of parasitized RBCs in patients with falciparum malaria after artemisinin treatment, and parasite clearance after artesunate treatment can be markedly prolonged in falciparum malaria patients who have had a splenectomy [33]. A previous study showed that Plasmodium-infected erythrocytes lose their normal deformability and become susceptible to splenic filtration, and splenic clearance of erythrocytes is enhanced by antimalarial therapy and splenomegaly [34]. The intact splenic function is of utmost importance for the host's defense capacity against Plasmodium spp., not only because it limits the acute infection through the removal of parasites from the blood stream, but also because it modulates parasite antigen expression on the surface of infected RBCs as well as cellular and humoral immune responses [35]. Other causes of immune suppression, such as cancer, may possibly reactivate latent malaria parasites [36]. Falciparum malaria infection is common in pregnant women and anemia is an important complication [37]. HIV infection may defects in macrophage phagocytosis, which diminish the spleen's ability to clear infection, causes the rapid onset of cerebral malaria in children [38].

The delay in parasite clearance has also been reported in a splenectomized patient with $P$. knowlesi malaria [39]. In a prospective controlled study of 33 previously splenectomized Malawian adults, parasite densities of $P$. falciparum reached significantly higher levels, and mature parasite stages were more often seen in the peripheral blood of asplenic individuals [40]. In areas endemic for P. falciparum, fever and parasitemia are significantly more frequent in splenectomized patients than in spleen-intact patients [40-42]. Splenectomized patients are at high risk of developing a more severe and fatal disease, even if they acquired semi-immunity prior to the loss of splenic tissue $[29,33,35,43]$. In this case, the patient's main symptoms were fever and parasitemia. The parasitemia declined slowly following artemisinin treatment. The morphology of the parasites in the blood films, with pyknotic nuclei and shrunken cytoplasm, suggested that they were dead. Although drug-affected parasites have clearly abnormal shapes, it is not easy to distinguish live parasites from dead ones. Malaria parasites were observed in blood films until Day 21 after continuous artemisinin treatment. Chotivanich et al. reported that patients without a functional spleen who have prolonged parasite clearance presumably do not require additional antimalarial treatment [33].

Recently, a molecular marker of artemisinin resistance was identified. Mutations in K13 propeller domain were shown to be associated with delayed parasite clearance in vitro and in vivo $[44,45]$. The detection of molecular mutations associated with K13 will greatly facilitate the tracking of artemisinin resistance as it emerges. In the case reported in this paper, prolonged parasite clearance was found after treatment with artesunate and ACT. The patient had a splenectomy due to a traffic accident 8 years ago from the time he was admitted to hospital and no mutation was found in the K13 propeller gene. Therefore, this case was finally identified as prolonged parasite clearance by splenectomy.

\section{Conclusion}

This paper reports a case of prolonged parasite clearance in a splenectomized Chinese worker with falciparum malaria imported from Nigeria. Artemisinin resistance should be distinguished when prolonged parasite clearance is found in a malaria patient who has had splenectomy.

\section{Additional file}

Additional file 1: Multilingual abstract in the five official working languages of the United Nations. (PDF 694 kb)

\section{Abbreviations}

ACT: Artemisinin-based combination therapy; PCR: Polymerase chain reaction; RBC: Red blood cell; WHO: World Health Organization

Acknowledgements

We thank Dr. Yao-Hui Bai for editing this report.

\section{Funding}

This work was supported by Project of Science and Technique of Henan, China (No. 092102310007), Project of Medical Science and Technique of Henan, China (No. 201304053), and the Special Funding of the Henan Health Science and Technology Innovation Talent Project (No.4045). The funders had no role in study design, data collection and analysis, decision to publish, or preparation of the paper.

Availability of data and materials

All data generated or analyzed during this study are included in this article.

Authors' contributions

H-WZ and S-JL designed the study. H-WZ and TH wrote the paper. S-JL, JT, and $\mathrm{Y}$-XS administered the study. Y-MY did the microscopic examination. YL and $\mathrm{C}-\mathrm{YY}$ confirmed the results. R-MZ completed the molecular identification of falciparum malaria. B-LX and Z-CF conceived the study and helped to develop the hypothesis. J-JW and X-YW completed the data collect and conducted the statistical analysis. All authors reviewed and approved the final version of the paper submitted to the journal.

Competing interests

The authors declare no conflicts of interest. 


\section{Consent for publication}

Written informed consent was obtained from the patient for the publication of this manuscript.

\section{Ethics approval and consent to participate}

Ethics approval was obtained from the 6th People's Hospital of Zhengzhou. Written informed consent was obtained from the patient for this paper to be published.

\begin{abstract}
Author details
${ }^{1}$ Department of Parasite Disease Control and Prevention, Henan Center for Disease Control and Prevention, Zhengzhou, People's Republic of China. ${ }^{2}$ Department of Infectious Diseases, the 6th People's Hospital of Zhengzhou, Zhengzhou 450016, People's Republic of China. ${ }^{3}$ School of Medicine and Health Management, Tongji Medical College, Huazhong University of Science and Technology, Wuhan 430030, Hubei, People's Republic of China.
\end{abstract}

\section{Received: 26 July 2016 Accepted: 15 February 2017}

\section{Published online: 04 April 2017}

\section{References}

1. Mebius RE, Kraal G. Structure and function of the spleen. Nat Rev Immunol. 2005:5:606-16.

2. Engwerda $\mathrm{CR}$, Beattie $\mathrm{L}$, Amante $\mathrm{FH}$. The importance of the spleen in malaria. Trends Parasitol. 2005;21:75-80.

3. Saunders $D$, Khemawoot $P$, Vanachayangkul $P$, Siripokasupkul $R$, Bethell $D$, Tyner S, Se Y, Rutvisuttinunt W, Sriwichai S, Chanthap L, et al. Pharmacokinetics and pharmacodynamics of oral artesunate monotherapy in patients with uncomplicated Plasmodium falciparum malaria in western Cambodia. Antimicrob Agents Chemother. 2012;56:5484-93.

4. Lopera-Mesa TM, Doumbia S, Chiang S, Zeituni AE, Konate DS, Doumbouya M, Keita AS, Stepniewska K, Traore K, Diakite SA, et al. Plasmodium falciparum clearance rates in response to artesunate in Malian children with malaria: effect of acquired immunity. J Infect Dis. 2013;207:1655-63.

5. WHO: Status report on artemisinin resistance-September 2014. World Health Organization 2014. http://www.who.int/malaria/publications/atoz/status-repartemisinin-resistance-sept2015.pdf.

6. Zhang HW, Liu Y, Zhang SS, Xu BL, Li WD, Tang JH, Zhou SS, Huang F. Preparation of malaria resurgence in China: case study of vivax malaria reemergence and outbreak in Huang-Huai Plain in 2006. Adv Parasitol. 2014;86:205-30.

7. Clements AC, Barnett AG, Cheng ZW, Snow RW, Zhou HN. Space-time variation of malaria incidence in Yunnan province, China. Malar J. 2009:8:180.

8. Xiao D, Long Y, Wang S, Wu K, Xu D, Li H, Wang G, Yan Y. Epidemic distribution and variation of Plasmodium falciparum and Plasmodium vivax malaria in Hainan, China during 1995-2008. Am J Trop Med Hyg. 2012;87:646-54.

9. Zhang HW, Su YP, Zhao XD, Yan QY, Liu Y, Chen JS. [Imported falciparum malaria situation in Henan Province during 2005-2009]. Zhongguo Ji Sheng Chong Xue Yu Ji Sheng Chong Bing Za Zhi. 2010;28:476-7.

10. Feng J, Yan H, Feng XY, Zhang L, Li M, Xia ZG, Xiao N. Imported malaria in China, 2012. Emerg Infect Dis. 2014;20:1778-80.

11. Liu Y, Zhang HW, Zhou RM, Yang CY, Qian D, Zhao YL, Xu BL. First imported relapse case of Plasmodium vivax malaria and analysis of its origin by CSP sequencing in Henan Province, China. Malar J. 2014;13:448.

12. Liu Y, Hsiang MS, Zhou H, Wang W, Cao Y, Gosling RD, Cao J, Gao Q. Malaria in overseas labourers returning to China: an analysis of imported malaria in Jiangsu Province, 2001-2011. Malar J. 2014;13:29.

13. $\mathrm{MOH}$ : Action Plan of China Malaria Elimination (2010-2020). Ministry of Health; 2010. http://www.nhfpc.gov.cn/zwgkzt/wsbysj/201005/47529.shtml.

14. WHO. Guidelines for the treatment of malaria. In guidelines for the treatment of malaria. 2nd ed. Geneva: World Health Organization; 2010. WHO Guidelines Approved by the Guidelines Review Committee].

15. Chen C. Development of antimalarial drugs and their application in China: a historical review. Infect Dis Poverty. 2014;3:9.

16. White NJ. Qinghaosu (artemisinin): the price of success. Science. 2008;320:330-4

17. Amaratunga C, Sreng S, Suon S, Phelps ES, Stepniewska K, Lim P, Zhou C, Mao S, Anderson JM, Lindegardh N, et al. Artemisinin-resistant Plasmodium falciparum in Pursat province, western Cambodia: a parasite clearance rate study. Lancet Infect Dis. 2012;12:851-8.
18. Noedl H, Se Y, Schaecher K, Smith BL, Socheat D, Fukuda MM. Evidence of artemisinin-resistant malaria in western Cambodia. N Engl J Med. 2008;359:2619-20

19. Miotto O, Almagro-Garcia J, Manske M, Macinnis B, Campino S, Rockett KA, Amaratunga C, Lim P, Suon S, Sreng S, et al. Multiple populations of artemisinin-resistant Plasmodium falciparum in Cambodia. Nat Genet. 2013;45:648-55.

20. Anderson TJ, Nair S, Nkhoma S, Williams JT, Imwong M, Yi P, Socheat D, Das D, Chotivanich K, Day NP, et al. High heritability of malaria parasite clearance rate indicates a genetic basis for artemisinin resistance in western Cambodia. J Infect Dis. 2010;201:1326-30.

21. Noedl H, Se Y, Sriwichai S, Schaecher K, Teja-Isavadharm P, Smith B, Rutvisuttinunt W, Bethell D, Surasri S, Fukuda MM, et al. Artemisinin resistance in Cambodia: a clinical trial designed to address an emerging problem in Southeast Asia. Clin Infect Dis. 2010;51:e82-9.

22. Satimai W, Sudathip P, Vijaykadga S, Khamsiriwatchara A, Sawang S, Potithavoranan T, Sangvichean A, Delacollette C, Singhasivanon P, Kaewkungwal J, Lawpoolsri S. Artemisinin resistance containment project in Thailand. II: Responses to mefloquine-artesunate combination therapy among falciparum malaria patients in provinces bordering Cambodia. Malar J. 2012;11:300

23. Na-Bangchang $K$, Karbwang J. Emerging artemisinin resistance in the border areas of Thailand. Expert Rev Clin Pharmacol. 2013;6:307-22.

24. Carrara VI, Lwin KM, Phyo AP, Ashley E, Wiladphaingern J, Sriprawat K, Rijken M, Boel M, Mcgready R, Proux S, et al. Malaria burden and artemisinin resistance in the mobile and migrant population on the Thai-Myanmar border, 1999-2011: an observational study. Plos Med. 2013;10:e1001398.

25. Flegg JA, Metcalf C, Gharbi M, Venkatesan M, Shewchuk T, Hopkins Sibley C, Guerin PJ. Trends in antimalarial drug use in Africa. Am J Trop Med Hyg. 2013:89:857-65.

26. Wernsdorfer $\mathrm{WH}$, Payne $\mathrm{D}$. The dynamics of drug resistance in Plasmodium falciparum. Pharmacol Ther. 1991;50:95-121.

27. Ajayi NA, Ukwaja KN. Possible artemisinin-based combination therapyresistant malaria in Nigeria: a report of three cases. Rev Soc Bras Med Trop. 2013;46:525-7.

28. Repetto EC, Traverso A, Giacomazzi CG. Possible clinical failure of artemether-lumefantrine in an italian traveler with uncomplicated falciparum malaria. Mediterr J Hematol Infect Dis. 2011;3:e2011041.

29. Demar M, Legrand E, Hommel D, Esterre P, Carme B. Plasmodium falciparum malaria in splenectomized patients: two case reports in French Guiana and a literature review. Am J Trop Med Hyg. 2004;71:290-3.

30. Le TA, Davis TM, Tran QB, Nguyen VP, Trinh KA. Delayed parasite clearance in a splenectomized patient with falciparum malaria who was treated with artemisinin derivatives. Clin Infect Dis. 1997;25:923-5.

31. Looareesuwan S, Suntharasamai P, Webster HK, Ho M. Malaria in splenectomized patients: report of four cases and review. Clin Infect Dis. 1993;16:361-6.

32. Cesta MF. Normal structure, function, and histology of the spleen. Toxicol Pathol. 2006:34:455-65.

33. Chotivanich $K$, Udomsangpetch $R$, Mcgready $R$, Proux $S$, Newton $P$, Pukrittayakamee S, Looareesuwan S, White NJ. Central role of the spleen in malaria parasite clearance. J Infect Dis. 2002;185:1538-41.

34. Looareesuwan $\mathrm{S}$, Ho M, Wattanagoon $Y$, White NJ, Warrell DA, Bunnag D, Harinasuta T, Wyler DJ. Dynamic alteration in splenic function during acute falciparum malaria. N Engl J Med. 1987;317:675-9.

35. Grobusch MP, Borrmann S, Omva J, Issifou S, Kremsner PG. Severe malaria in a splenectomised Gabonese woman. Wien Klin Wochenschr. 2003;115:63-5.

36. Foca E, Zulli R, Buelli F, De Vecchi M, Regazzoli A, Castelli F. P. falciparum malaria recrudescence in a cancer patient. Infez Med. 2009;17:33-4.

37. Cisse M, Sangare I, Lougue G, Bamba S, Bayane D, Guiguemde RT. Prevalence and risk factors for Plasmodium falciparum malaria in pregnant women attending antenatal clinic in Bobo-Dioulasso (Burkina Faso). BMC Infect Dis. 2014;14:631

38. Joice R, Frantzreb C, Pradham A, Seydel KB, Kamiza S, Wirth DF, Duraisingh MT, Molyneux ME, Taylor TE, Marti M, Milner Jr DA. Evidence for spleen dysfunction in malaria-HIV co-infection in a subset of pediatric patients. Mod Pathol. 2016;29:381-90.

39. Boo YL, Lim HT, Chin PW, Lim SY, Hoo FK. A case of severe Plasmodium knowlesi in a splenectomized patient. Parasitol Int. 2016;65:55-7.

40. Bach O, Baier M, Pullwitt A, Fosiko N, Chagaluka G, Kalima M, Pfister W, Straube E, Molyneux M. Falciparum malaria after splenectomy: a prospective 
controlled study of 33 previously splenectomized Malawian adults. Trans R Soc Trop Med Hyg. 2005;99:861-7.

41. Boone KE, Watters DA. The incidence of malaria after splenectomy in Papua New Guinea. BMJ. 1995;311:1273.

42. Israeli A, Shapiro M, Ephros MA. Plasmodium falciparum malaria in an asplenic man. Trans R Soc Trop Med Hyg. 1987;81:233-4.

43. Petithory JC, Khelil A, Galeazzi G, Ardoin F. Malaria in splenectomized patients. Three fatal cases. Presse Med. 2005;34:519-21.

44. Tun KM, Imwong M, Lwin KM, Win AA, Hlaing TM, Hlaing T, Lin K, Kyaw MP, Plewes K, Faiz MA, et al. Spread of artemisinin-resistant Plasmodium falciparum in Myanmar: a cross-sectional survey of the K13 molecular marker. Lancet Infect Dis. 2015;5(4):415-21.

45. Takala-Harrison S, Jacob CG, Arze C, Cummings MP, Silva JC, Dondorp AM, Fukuda MM, Hien TT, Mayxay M, Noedl H, et al. Independent Emergence of Artemisinin Resistance Mutations Among Plasmodium falciparum in Southeast Asia. J Infect Dis. 2015;211:670-9.

Submit your next manuscript to BioMed Central and we will help you at every step:

- We accept pre-submission inquiries

- Our selector tool helps you to find the most relevant journal

- We provide round the clock customer support

- Convenient online submission

- Thorough peer review

- Inclusion in PubMed and all major indexing services

- Maximum visibility for your research

Submit your manuscript at www.biomedcentral.com/submit
C) Biomed Central 